\title{
Incidental prostate cancer prevalence at radical cystoprostatectomy-importance of the histopathological work-up
}

\author{
C. Wetterauer • M. Weibel • J. R. Gsponer • T. Vlajnic • \\ T. Zellweger • S. Bütikofer • G. Müller • H. Püschel •
}

A. Bachmann - T. C. Gasser - L. Bubendorf • C. A. Rentsch

Received: 12 May 2014 / Revised: 25 August 2014 / Accepted: 12 September 2014 /Published online: 1 October 2014

(C) Springer-Verlag Berlin Heidelberg 2014

\begin{abstract}
The reported incidental prostate cancer prevalence rates at radical cystoprostatectomy cover a range from 4 to $60 \%$. We investigated the influence of the histopathological work-up on prostate cancer prevalence rates. We identified 114 patients who had undergone cystoprostatectomy for bladder cancer between 2000 and 2012. Complete histopathological assessment was defined as follows: (i) complete embedding of the prostate gland, (ii) sectioning of 15 or more prostate sections, and (iii) processing as whole mount slides. Prostate cancer prevalence rates derived from complete and incomplete histopathological assessments were compared. The overall prostate cancer prevalence rate was $59.6 \%$. A mean of 14.4 macroscopic tissue sections (thickness 3-5 mm) were sectioned. Sectioning $\geq 15$ sections resulted in a prostate cancer detection rate of $75 \%$, compared to $42.6 \%$ when sectioning $<15$ sections $(p<0.001)$. Complete embedding yielded a prostate cancer detection rate of 72.3 and of $23.1 \%$ for partly embedded prostates $(p<0.0001)$. Prostate cancer was detected in $68.8 \%$ of the whole mounted samples and in $38.2 \%$ of the samples sectioned as standard slides $(p<0.01)$; according to the criteria described by Epstein and Ohori, $44.1 \%$ of the detected prostate cancers were clinically significant. The quality of the histopathological work-up significantly influences prostate cancer detection rates and might
\end{abstract}

C. Wetterauer and M. Weibel contributed equally to this work.

C. Wetterauer · S. Bütikofer · G. Müller · H. Püschel ·

A. Bachmann - T. C. Gasser C C. A. Rentsch ( $\square)$

Department of Urology, University Hospital Basel, Spitalstrasse 21,

4031 Basel, Switzerland

e-mail: crentsch@uhbs.ch

M. Weibel • J. R. Gsponer · T. Vlajnic $\cdot$ H. Püschel $\cdot$ L. Bubendorf Institute of Pathology, University Hospital Basel, Basel, Switzerland

T. Zellweger

Clara Hospital Basel, Basel, Switzerland at least partially explain the highly variable reported incidental prostate cancer prevalence rates at cystoprostatectomy (CP). The high proportion of significant prostate cancer found in our series calls for a careful surgical approach to the prostate during $\mathrm{CP}$.

Keywords Incidental prostate cancer $\cdot$ Bladder cancer . Radical cystoprostatectomy $\cdot$ Histology

\section{Introduction}

With a proportion of $24.4 \%$ of male malignancies, prostate cancer represents the most common solid neoplasm among men [28]. Bladder cancer makes up $6.3 \%$ of all cancers among men in Europe and ranks as the 4th most common cancer for men, with approximately 95,000 newly diagnosed cases each year $[13,28]$. The prevalence of both prostate and bladder cancers increases in the aging population. As radical cystoprostatectomy $(\mathrm{CP})$ is performed mostly in elderly patients, the coincidental detection of both tumors is not uncommon. Highly variable prevalence rates of incidental prostate cancer at radical CP have been reported, ranging from 4 [30] to $60 \%$ [29]. Importantly, the histopathological work-up of the prostate, more specifically, the macroscopic section thickness [3, 11] and the embedding technique [3, 14], is known to influence prostate cancer detection rates. Here, we assessed the prevalence rate of incidental prostate cancer in CP specimens in a highly industrialized town area and compared our findings to the reported rates worldwide. Furthermore, we analyzed the histopathological characteristics, their potential clinical relevance, and the influence of the histopathological technique on the detection of incidental prostate cancer. 


\section{Materials and methods}

This retrospective study was approved by the local ethics committee (EKBB). One hundred thirty-nine patients having undergone radical CP for bladder cancer $(n=133)$ and other indications between 2000 and 2012 were identified by searches in the archives of the Departments of Urology and Pathology at University Hospital Basel and by searches in the accounting systems. Twenty-five of these patients did not qualify for the analysis because either prostate cancer had been diagnosed prior to surgery or they had been treated for other reasons $(n=6)$ than bladder cancer like low-capacity bladder or contracted, nonfunctional bladder after radiation therapy. Finally, 114 men who had undergone radical CP for bladder cancer were included in the analysis. The medical reports were reviewed for individual patient characteristics. The histopathology reports were screened for the TNM classification of bladder and prostate cancers and for tumor histology, including Gleason score, surgical margins, maximal tumor diameter, complete or partial sampling, and number of macroscopic sections. All histological samples were reviewed according to the current classifications (i.e., TNM 2009, WHO 2004, ISUP 2005)

To determine the maximal tumor diameter, the edges of each tumor were outlined and the resulting distances were measured in millimeters; if a tumor was present in consecutive sections, the greatest measurement in all three dimensions (length, width, or depth) was considered the maximum diameter. In patients with complete transurethral resection of bladder (TUR-B) tumors and no evidence of tumors in the bladder at cystectomy, the final histology at TUR-B before the cystectomy was noted. Radical CP samples were processed in accordance with the descriptions in the guidelines of the Swiss Society of Pathology [12]. For histopathological grading, the 2004 WHO classification was used.

For macroscopic tissue sectioning, a mean of 14.4 (median 15 , range 2-37) sections with a thickness between 3 and $5 \mathrm{~mm}$ were used. Of the total 114 processed samples, 26 (23.1\%) had been partially and 83 (76.1\%) had been completely embedded. For five samples, no information on the completeness of the embedding was available. Eighty (70.2 \%) samples were prepared as whole mount sections, and 34 (29.8\%) samples were processed as standard specimen slides.

We applied the following most commonly used criteria for nonsignificant prostate cancer [22]: (i) Gleason score $\leq 6$ without Gleason pattern 4 or 5, (ii) organ-confined disease, and (iii) tumor volume $<0.5 \mathrm{~cm}^{3}$.

To determine the maximal tumor diameter, the edges of each tumor were outlined and the resulting distances were measured in millimeters; if a tumor was present in consecutive sections, the greatest measurement in all three dimensions (length, width, or depth) was considered the maximum diameter. Pathological reports did not encompass tumor volume but did indicate tumor diameter. Based on the mathematical formula of spherical volume $\left(4 / 3 \pi r^{3}\right)$, we calculated the diameter for a tumor with a volume of $0.5 \mathrm{~cm}^{3}$ and concluded that a tumor with a diameter larger than $1 \mathrm{~cm}$ would therefore be defined as significant.

All statistical inference testing and data visualization were performed using R 3.0.1. [24]. For continuous data, Wilcoxon rank sum tests were used, and for categorical data, Fisher's exact tests or Pearson's chi-squared tests were applied as indicated. The clinical follow-up information regarding PSA course, survival, progression, or recurrence was incomplete, and the data quality did not allow for further statistical analysis. $P$ values lower than 0.05 were considered statistically significant.

\section{Results}

Detailed characteristics for all 114 bladder cancer patients are given in Table 1. Most of the detected bladder cancers were diagnosed as urothelial carcinomas $(n=108 ; 94.7 \%)$, while the remaining diagnoses were small cell carcinoma, sarcomatoid carcinoma, squamous cell carcinoma, mixed carcinoma, and urothelial dysplasia.

Incidental prostate cancer was identified in $68(59.6 \%)$ of the $114 \mathrm{CP}$ specimens. The patient characteristics for the patients with incidental prostate cancer are given in Table 2. All prostate cancers were histologically classified as adenocarcinomas. In three patients, high-grade prostatic intraepithelial neoplasia (PIN) was diagnosed. Median age of patients with prostate cancer was comparable to that of the whole investigated population, and no significant difference in age between patients with (69.4 years) and without (69.7 years) prostate cancer was observed. Four (5.9\%) had a Gleason score of 4 . The majority of patients $(n=45)$ exhibited a Gleason score of 5-6 (66.2\%), and 19 patients (27.9\%) had Gleason scores $\geq 7$. Sixty-one $(89.7 \%)$ of the 68 tumors displayed organ-confined growth, while extra-capsular extensions were observed in 7 (10.3\%). Of note, none of the 67 prostate cancer patients for whom the lymph node status had been determined demonstrated lymph node metastases. The mean number of resected lymph nodes was 15.5 (median 13.5; range 2-37). Overall, 62 (91.2\%) of the specimens showed tumor-free surgical margins (R0), and $6(8.8 \%)$ displayed positive margins (R1). Positive margins were identified dorsally $(n=1)$, laterally $(n=1)$, in the apex $(n=2)$, and the basis $(n=2)$.

PSA had been tested prior to surgery for 32 patients and upon follow-up for 20 patients. The mean PSA prior to surgery was $2.78 \mathrm{ng} / \mathrm{ml}$ (median $1.55 \mathrm{ng} / \mathrm{ml}$, range 0.03 $12 \mathrm{ng} / \mathrm{ml}$ ). The mean preoperative PSA value of the groups with prostate cancer $(3.3 \mathrm{ng} / \mathrm{ml})$ and without detected prostate cancer $(1.1 \mathrm{ng} / \mathrm{ml}$ ) was significantly different (Fig. $1, p<0.05$, 
Table 1 Descriptive characteristics of bladder cancer detected in cystoprostatectomy specimens

\begin{tabular}{|c|c|c|}
\hline $\begin{array}{l}\text { Number of patients } \\
\text { age (years) }\end{array}$ & 114 & \\
\hline median & 69.7 & \\
\hline range & $44-88$ & \\
\hline T stage & $n$ & $\%$ \\
\hline $\mathrm{Ta}$ & 1 & 0.9 \\
\hline cis & 7 & 6.1 \\
\hline $\mathrm{T} 1$ & 13 & 11.4 \\
\hline $\mathrm{T} 2$ & 40 & 35.1 \\
\hline $\mathrm{T} 3$ & 2 & 1.8 \\
\hline $\mathrm{T} 3 \mathrm{a}$ & 18 & 15.8 \\
\hline $\mathrm{T} 3 \mathrm{~b}$ & 15 & 13.2 \\
\hline T3 total & 35 & 30.7 \\
\hline T4 total & 18 & 15.8 \\
\hline Concomitant $\mathrm{Cis}$ & 20 & 17.5 \\
\hline \multicolumn{3}{|l|}{ Grade } \\
\hline G2 & 18 & 16.8 \\
\hline G3 & 96 & 84.2 \\
\hline \multicolumn{3}{|l|}{$\mathrm{pN}$ stage } \\
\hline N0 & 83 & 72.8 \\
\hline N1 & 18 & 15.8 \\
\hline $\mathrm{N} 2$ & 12 & 10.5 \\
\hline $\mathrm{Nx}$ & 1 & 0.9 \\
\hline \multicolumn{3}{|l|}{ Distant metastases } \\
\hline M0 & 100 & 87.7 \\
\hline M1 & 1 & 0.9 \\
\hline Not reported & 13 & 11.4 \\
\hline \multicolumn{3}{|l|}{ Resection margin } \\
\hline R0 & 101 & 88.6 \\
\hline $\mathrm{R} 1$ & 13 & 11.4 \\
\hline \multicolumn{3}{|l|}{ Histology } \\
\hline Urothelial carcinoma & 108 & 94.7 \\
\hline Others & 6 & 5.3 \\
\hline
\end{tabular}

Wilcoxon rank sum test). In the low PSA group (PSA $<4 \mathrm{ng} / \mathrm{ml})$, prostate cancer was detected in $20(70.4 \%)$ of the 27 patients; 7 (41.2\%) cases were significant. Prostate cancer was detected in all five patients with a PSA $>5 \mathrm{ng} / \mathrm{ml}$. The comparison of the PSA values prior to surgery $(n=31)$ correlated positively with the tumor diameter $(p=0.0071$, Spearman rho $\left.=0.58, R^{2}=0.33\right)$. After surgery, the PSA dropped to a mean of $0.034 \mathrm{ng} / \mathrm{ml}$ (median $<0.03$, range $<0.03-0.09)$. Additionally, $30(44.1 \%)$ of the 68 detected prostate cancers fulfilled the criteria for a significant carcinoma. Eighteen tumors had a Gleason pattern of 4 or higher, 23 featured a diameter greater than $10 \mathrm{~mm}, 7$ were not organ confined, and 13 met several of the criteria for clinical significance (Table 3). The mean preoperative PSA in the subgroup of insignificant prostate cancer $(1.4 \mathrm{ng} / \mathrm{ml})$ was significantly lower than the mean PSA in the subgroup of significant prostate cancer (5.4 ng/ml, $p=<0.01)$ (Fig. 1).
Table 2 Descriptive characteristics of incidentally detected prostate cancer

Number of patients

68

Histology

Adeno-ca

68

T stadium

$\mathrm{T} 2$

$\mathrm{T} 2 \mathrm{a}$

$\mathrm{T} 2 \mathrm{~b}$

$\mathrm{T} 2 \mathrm{c}$

T2 total

$\mathrm{T} 3$

$\mathrm{T} 3 \mathrm{a}$

T3 total

$\mathrm{pN}$ stage

N0

N1

$\mathrm{Nx}$

Resected LN ( $n=$

36)

Mean

15.5

Median

13.5

Range

2-37

Distant metastases

M1

M0

\section{0}

57

Unknown

11

83.8

Gleason score

Median

$2+2$

$2+3$

$3+2$

$3+3$

$3+4$

7

$3+5$

$4+3$

$4+5$

$5+3$

Tumor diameter

(mm)

Mean

Median

Range

Tumor volume $\left(\mathrm{cm}^{3}\right)$

Mean

Range

\section{6}

4

6

5

34

10

1

1

5

1

1

9.6

8

1-44

$n=68$

In the group with incidental prostate cancer, a mean of 16.4 (median 17, range 5-34) tissue sections were sectioned. Fewer than 15 sections were used for $54(47.4 \%)$ of the prostates, and 15 or more sections were used for 60 (52.6\%) prostates. 


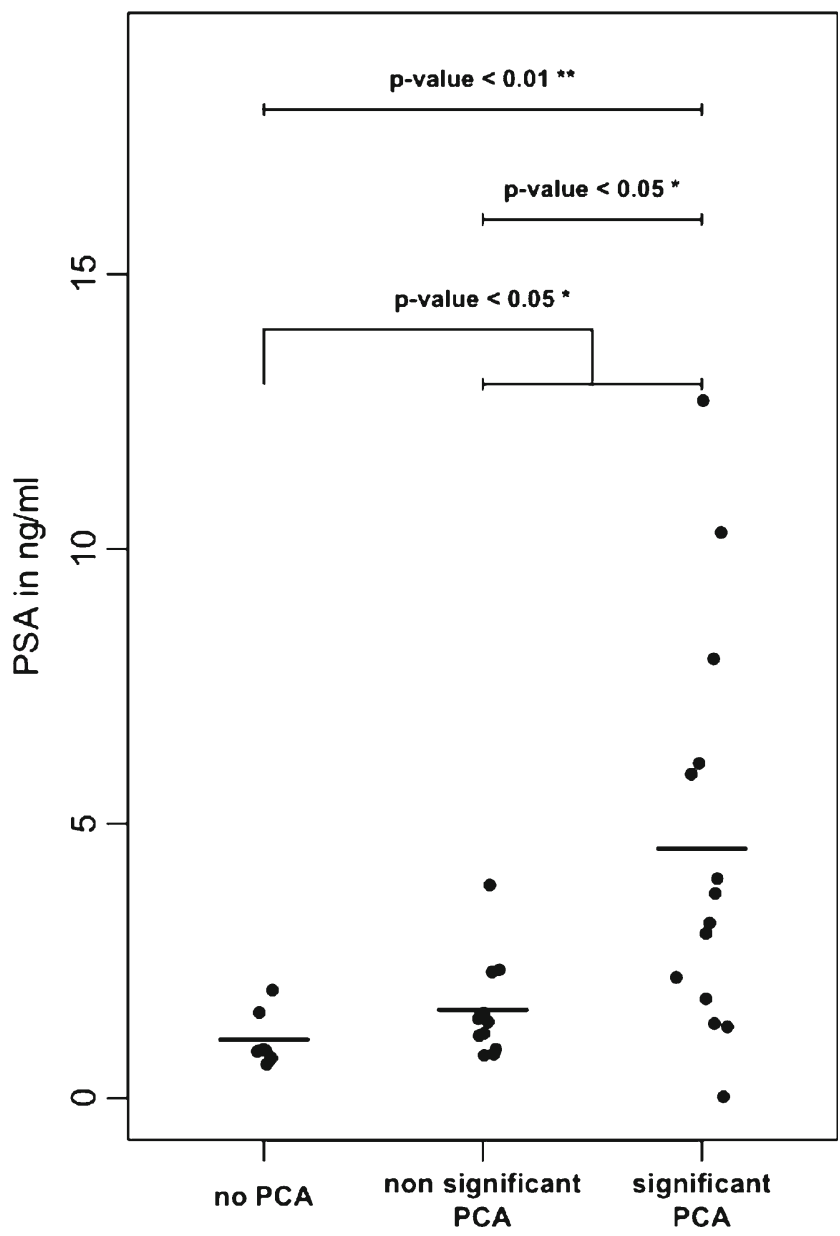

Fig. 1 Comparison of preoperative PSA values in the groups without, with nonsignificant, and with significant prostate cancer

This resulted in the detection of $23(42.6 \%)$ and $45(75 \%)$ incidental prostate cancers $(p<0.001$; Fisher's exact test), respectively, as presented in Fig. 2. Eighty-three (76.1\%) of the total 114 prostates were embedded completely, and 26 $(23.9 \%)$ were embedded partially. For five prostates, the embedding technique was not reported. Prostate cancer was detected in $60(72.3 \%)$ of the 83 completely embedded samples and in $6(23.1 \%)$ of the 26 partially embedded

Table 3 Further criteria for the clinical relevance of prostate cancer $(n=$ patients with prostate cancer fulfilling the indicated criteria)

\begin{tabular}{lll}
\hline & Number & Percent \\
\hline Gleason score including a pattern $\geq 4$ & 18 & 26.5 \\
pT stage $\geq$ T3 & 7 & 10.3 \\
Max tumor diameter $>10 \mathrm{~mm}$ & 23 & 33.8 \\
More than one criterion for relevant cancer & 13 & 19.1 \\
$<60$ years & 13 & 19.1 \\
$\geq 60<75$ years & 35 & 51.5 \\
$\geq 75$ years & 20 & 29.4 \\
Total clinical relevant tumors & 30 & 44.1 \\
\hline
\end{tabular}

samples $(p<0.0001$; Fisher's exact test; Fig. 2). Significant prostate cancer was detected in $28(33.7 \%)$ of the 83 completely embedded samples and in $1(3.8 \%)$ of the 26 partially embedded samples ( $p<0.01$; Fisher's exact test).

We compared the rates of complete embedding with the detection rate of prostate cancer in the periods between 2000 and 2006 and 2007 and 2012. The rates of completely embedded samples in the two periods were 55.3 and $91.9 \%$, respectively. The first period yielded an overall prostate cancer prevalence rate of $50 \%$, and the second period yielded $67.7 \%$.

Whole mount sections were used for 80 (70.2\%) samples, and standard slides were used for 34 (29.8\%) samples. In 55 $(68.8 \%)$ of the whole mount sections and in $13(38.2 \%)$ of the standard slides, prostate cancer could be detected $(p<0.01$; Fisher's exact test; Fig. 2).

\section{Discussion}

Here, we explored the prevalence of incidental prostate cancers in CP specimens in a highly industrialized town area, where most of the CP specimens are processed centrally at a single pathology institute. Comparison of complete versus incomplete specimen processing indicated prostate cancer prevalence rates reaching up to $75 \%$ for completely processed specimens.

Based on previous publications, including a total of 11,553 patients, the mean prevalence rates of prostate cancer at radical CP in Europe and globally were 25.2 and $26.5 \%$, respectively (Table 4). Detection rates are influenced by technical variables [3, 11], study populations [3], and geographic [23, 28] factors; e.g., studies from Asia generally reported lower rates than those from the USA and Europe (Table 4). Compared to these previously reported rates, the $59.6 \%$ in our study represent one of the highest published prevalence rates of incidental prostate cancer in CP specimens (Table 4). Generating a best-case scenario and analyzing the subgroup of 53 patients with complete embedding, the use of 15 or more sections and whole mount sections results in a prevalence rate of $75.5 \%$. This extraordinary high proportion is unlikely to be greatly biased by the retrospective nature of the study because our study was based on a consecutive series of CP specimens. Our high prevalence of incidental prostate cancer also clearly exceeded the rates of most previous autopsy series [7]. Only Sakr et al. discovered unexpected prostate cancer at a similarly high rate of 55 and $64 \%$ of autopsied patients who had died in their 6th and 7th decades, respectively, after a histological examination of their whole prostates [25].

To the best of our knowledge, this is the first report on the prevalence of incidental prostate cancer in $\mathrm{CP}$ specimens in Switzerland. It could be speculated that the high prevalence in an industrialized town area may be due to an increased exposure to potential carcinogenic factors that drive prostate cancer. However, to date, there has been no published evidence 
a

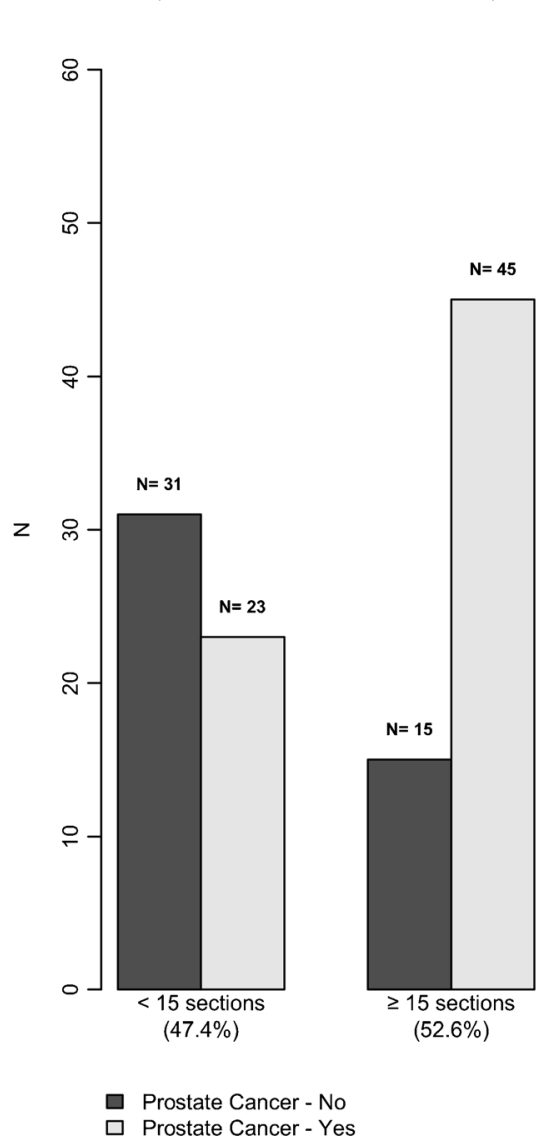

b

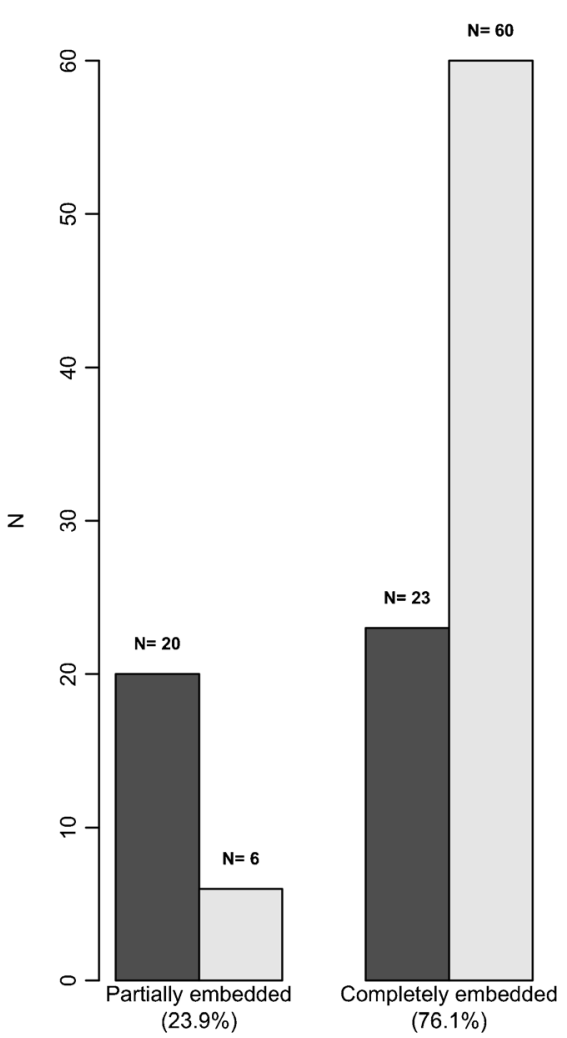

C

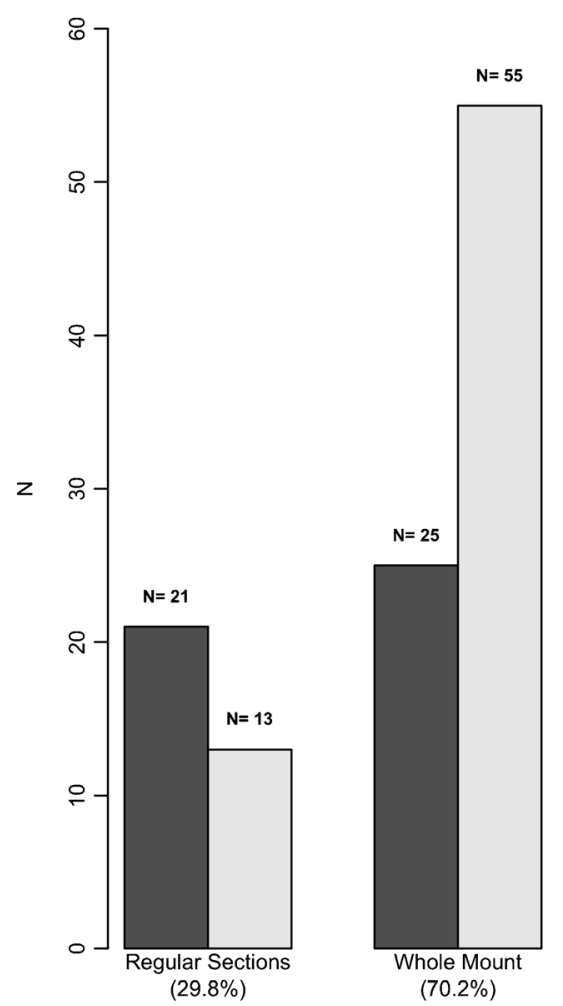

Fig. 2 Detection rates of incidental prostate cancer, according to the pathological work-up. a $<15$ versus $>15$ prostate sections. b Complete versus partial embedding. $\mathbf{c}$ Regular slides versus whole mount slides. The numbers in brackets indicate the percentage of specimens in each indicated group

that a high prevalence of incidental prostate cancer could be driven by exposure to carcinogens in the context of the substantial presence of chemical and pharmaceutical industries or by other, as yet undefined, exposures in our region.

Instead, the extent of histological processing appears to be the most influential factor to explain the high prostate cancer prevalence (Fig. 2). Several published results have shown that lower section thickness increases prostate cancer detection rates $[11,30]$. In our study, the prostates were processed into $3-5 \mathrm{~mm}$ tissue slices and paraffin blocks, and sections from 15 or more tissue blocks significantly raised the prostate cancer detection rates. Although the section number can depend on the size of the prostate gland, our results suggest that prostate cancer detection rates increased proportionally with the number of tissue blocks and sections. The same was true for complete versus incomplete embedding of the prostate, which is in line with other published series [3, 14]. Furthermore, complete embedding significantly improved $(p<0.01)$ the detection of significant prostate cancer compared to partial embedding in our series. The use of the whole mount technique [19] resulted in a significantly $(p<0.01)$ higher prostate cancer detection rate of $68.8 \%$, compared to the use of regular slides (38.2\%). As a caveat, $89.3 \%$ of the prostates processed as whole mount sections, but only $26.5 \%$ of those processed as regular slides were completely embedded. Finally, the overall prostate cancer prevalence rate of $67.7 \%$ between 2007 and 2012, when most of the samples were embedded completely, indicates that a consequent use of complete embedding, the use of whole mount sections, and/or a high section number can significantly influence the prostate cancer prevalence rates in CP series.

The clinical relevance of incidental prostate cancers detected at radical CP remains questionable. Two studies demonstrated significantly worse survival after radical CP for patients with concurrent tumors [8, 27], while Pritchett found no difference in the mortality rates [11]. In a recent series of 1476 patients, $22 \%$ of the detected prostate cancers were classified as significant. However, the most influential factor in this series was not the presence of relevant prostate cancer but prostatic infiltration of a urothelial carcinoma [6]. In our series, almost half of the prostate cancers met criteria for significant prostate cancer (Table 3) but none had detectable lymph node metastases (Table 2). Our rate of clinically significant prostate cancer is comparable to the other reported rates (Table 4), even though the reported rates are diverse, based on the different criteria being applied [22]. Elevated 
Table 4 Worldwide reported rates of incidental prostate cancer in cystoprostatectomy specimens

\begin{tabular}{|c|c|c|c|c|c|c|c|c|c|}
\hline Author & Region & Year & $N$ & $\begin{array}{l}\text { Mean } \\
\text { age }\end{array}$ & $\begin{array}{l}\text { Section } \\
\text { thickness } \\
(\mathrm{mm})\end{array}$ & Sampling & $\begin{array}{l}\mathrm{PCa} \\
\text { total }\end{array}$ & $\begin{array}{l}\mathrm{PCa} \\
\%\end{array}$ & $\begin{array}{l}\text { Significant } \\
\text { PCa }(\%)\end{array}$ \\
\hline \multicolumn{10}{|l|}{ North America } \\
\hline Winfield [3] & Iowa, USA & 1987 & 80 & 63.7 & & Complete & 22 & 27.5 & $11(50 \%)$ \\
\hline Pritchett [11] & South Carolina, USA & 1988 & 165 & 65 & & Partial & 45 & 27.3 & $8(17.8 \%)$ \\
\hline Montie [11] & Cleveland, USA & 1989 & 84 & 62 & $4-5$ & Complete & 39 & 46.4 & $6(15 \%)$ \\
\hline Kabalin [3] & Standford, USA & 1989 & 66 & 64 & 3 & Complete & 25 & 37.9 & $3(12 \%)$ \\
\hline Abbas [11] & Miami, USA & 1996 & 40 & 64.3 & $2-3$ & Partial & 18 & 45 & \\
\hline Ward [3] & Rochester, USA & 2004 & 129 & 69 & & & 30 & 23.3 & $18(60 \%)$ \\
\hline Revelo [11] & Nashville, USA & 2004 & 121 & 67.4 & 5 & Complete & 50 & 41.3 & $24(48 \%)$ \\
\hline Abdelhady [3] & Ontario, Canada & 2007 & 204 & 67 & & Complete & 58 & 28.4 & $18(31 \%)$ \\
\hline Weizer [3] & Michigan, USA & 2007 & 35 & 65 & & & 16 & 45.7 & $4(25 \%)$ \\
\hline Bruins [6] & Los Angeles, USA & 2013 & 1476 & 69 & $3-5$ & & 559 & 37.9 & $123(8.3 \%)$ \\
\hline \multicolumn{10}{|l|}{ Europe } \\
\hline Moutzouris [11] & Athens, Greece & 1999 & 59 & 66.5 & 5 & Complete & 16 & 27.1 & \\
\hline Conrad [11] & Hamburg, Germany & 2001 & 133 & 60 & 3 & Complete & 58 & 43.6 & $11(19 \%)$ \\
\hline Prange [3] & Hamburg, Germany & 2001 & 85 & 64 & 4 & Complete & 41 & 49.0 & $4(10 \%)$ \\
\hline Cindolo [3] & Naples, Italy & 2001 & 165 & 69 & 3 & Partial/complete & 17 & 10.3 & \\
\hline Kouriefs [3] & Gillinghan, England & 2005 & 128 & & & & 23 & 18 & \\
\hline Delongchamp [11] & Paris, France & 2005 & 141 & 62 & 4 & Complete & 20 & 14.2 & $14(70 \%)$ \\
\hline Montironi [3] & Ancona, Italy & 2005 & 132 & 61 & & Complete & 55 & $42 \%$ & \\
\hline Ruffion [11] & Lyon, France & 2005 & 100 & 62 & 2.5 & Complete & 51 & 51 & $6(12 \%)$ \\
\hline Rocco [11] & Milano, Italy & 2006 & 63 & 67 & 3 & Complete & 34 & 54 & $12(35 \%)$ \\
\hline Winkler [29] & London, England & 2007 & 97 & & 2 & Partial & 58 & 60 & $31(53 \%)$ \\
\hline Barbisan [5] & Marche, Italy & 2008 & 248 & 68 & 3 & & 123 & 49.6 & $23(18.7 \%)$ \\
\hline Mazzuchelli [18] & Ancona, Italy & 2009 & 248 & 68 & 3 & Complete & 123 & 49.6 & $23(18.7 \%)$ \\
\hline Gakis [15] & Tübingen, Germany & 2010 & 95 & 68 & $4-5$ & & 26 & 27.4 & $7(27 \%)$ \\
\hline Buse [8] & Germany & 2012 & 1122 & 65.6 & $2-5$ & & 200 & 17.8 & \\
\hline Fritsche [14] & Regensburg, Germany & 2012 & 295 & 68 & 4 & Partial/complete & 91 & 30.8 & $41(45 \%)$ \\
\hline Alsinnawi [2] & Dublin, Ireland & 2012 & 108 & 64 & 4 & Complete & 35 & 32.4 & $10(28.5 \%)$ \\
\hline Sruogis [27] & Vilnius, Lithuania & 2012 & 81 & 61.3 & & & 27 & 33.3 & $13(48.1 \%)$ \\
\hline Pignot [21] & France & 2013 & 4251 & 70.2 & & & 905 & 21.7 & \\
\hline Wetterauer & Basel, Switzerland & 2013 & 115 & 68.9 & $3-5$ & Partial/complete & 68 & 59.6 & $40(58.8 \%)$ \\
\hline \multicolumn{10}{|l|}{ Asia } \\
\hline Lee $[30]$ & Kweishan, Taiwan & 2006 & 248 & 63 & 5 & Complete & 10 & 4 & \\
\hline Yang [30] & Thaijung, Taiwan & 1999 & 49 & 67.8 & 3 & Complete & 16 & 32.6 & \\
\hline Nakagawa [20] & Tokyo, Japan & 2009 & 349 & 65 & 5 & & 91 & 26.1 & $68(74.7 \%)$ \\
\hline $\operatorname{Jin}[16]$ & Hangzhou, China & 2008 & 264 & 70.9 & 5 & Complete & 37 & 14 & $12(32.4 \%)$ \\
\hline Zhu [30] & Shanghai, China & 2009 & 92 & 67.1 & 5 & Complete & 3 & 3.3 & $1(33.3 \%)$ \\
\hline \multicolumn{10}{|l|}{ Australia } \\
\hline Ahmadi [1] & Sydney, Australia & 2012 & 129 & & & & 50 & 38.8 & $35(70 \%)$ \\
\hline \multicolumn{10}{|l|}{ Middle east } \\
\hline Aydin [3] & Turkey & 1999 & 121 & 67.1 & & & 17 & 14 & \\
\hline Hosseini [3] & Theran, Iran & 2007 & 50 & 62.5 & & Partial & 7 & 14 & $4(57 \%)$ \\
\hline Aytac [4] & Bursa, Turkey & 2011 & 300 & 62 & $3-5$ & Complete & 60 & 20 & $40(66.7 \%)$ \\
\hline North America & & & 2400 & & & & 862 & 35.9 & \\
\hline Europe & & & 7551 & & & & 1903 & 25.2 & \\
\hline Asia & & & 1002 & & & & 157 & 15.7 & \\
\hline Australia & & & 129 & & & & 50 & 38.8 & \\
\hline Middle East & & & 471 & & & & 84 & 17.8 & \\
\hline Total & & & 11,553 & & & & 3056 & 26.5 & \\
\hline
\end{tabular}


PSA may be predictive of the presence of significant cancer and a large tumor diameter, as suggested by our comparison; however, the patient numbers are low, and the clinical data are insufficient for making final conclusions about these findings.

Srougi et al. proposed a cystectomy in combination with the enucleation of adenomas [3], and TUR-P with preservation of the capsule prior to cystectomy was reported as an option by Colombo et al. [10]. These techniques might be applicable for selected patients for whom the preservation of potency is paramount, but in light of our findings, they may stand against the principles of cancer surgery. If attempted though, it seems reasonable to perform prostate biopsy before such surgery as even low PSA values cannot exclude the presence of prostate cancer (Fig. 1). Given the high risk of prostate cancer in patients undergoing $\mathrm{CP}$, special attention to the removal of the prostate seems advisable. Once the presence of prostate cancer has been confirmed after CP, specific oncologic followup may be indicated. At least in high-risk prostate cancer, the oncologic follow-up might include regular PSA monitoring in order to detect residual, recurrent, or metastatic disease.

It has been suggested that bladder cancer patients have an increased risk of being diagnosed with prostate cancer [17, 26]. In fact, a higher coincidence rate of bladder and prostate tumors compared to their presence in the general population has been reported [9]. Such a correlation may be explained partly by the relatively high age of patients and the fact that exposure of patients with either tumor type to urologists favors the detection of other urogenital cancers, if present. Finally, there is currently no compelling evidence for a common link between prostate and bladder cancers.

Several studies have reported the influence of specific pathologic sampling techniques on prostate cancer detection rates in $\mathrm{CP}$ specimen. To the best of our knowledge, we are the first to assess the influence of specific aspects of pathologic sampling within one series at a single Pathology Institute and to report the incidental prevalence rate of $\mathrm{PCa}$ at $\mathrm{CP}$ in Switzerland. Compared to the extremely variable reported rates of incidentally discovered prostate cancers, our reported rate of $59.6 \%$ ranks among the highest published rates. Subgroup analysis of samples with complete embedding, the use of 15 or more sections, and whole mount sections resulted in prevalence rates of more than $75 \%$ in our series.

\section{Conclusions}

We report a high prevalence of incidental prostate cancer at $\mathrm{CP}$ of $59.6 \%$. This is more than twice as high as the mean reported European and worldwide prevalence of $26.5 \%$. We demonstrate the paramount importance of a complete histopathological work-up for estimating the true prevalence of prostate cancer in a given population and for the detection of significant prostate cancer. Our results call for a careful surgical approach to the prostate at radical cystoprostatectomy.

Conflict of interest The authors declare that they have no conflict of interest.

\section{References}

1. Ahmadi N, Delprado WJ, Brooks AJ, Brenner PC, Coombes GM, Grant A, Patel MI (2012) Cancer identified incidentally in the prostate following radical cystoprostatectomy: an Australian study. ANZ J Surg. doi:10.1111/ans.12015

2. Alsinnawi M, Loftus B, Flynn R, McDermott T, Grainger R, Thornhill JA (2012) The incidence and relevance of prostate cancer in radical cystoprostatectomy specimens. Int Urol Nephrol 44:17051710. doi:10.1007/s11255-012-0224-y

3. Autorino R, Di Lorenzo G, Damiano R, Giannarini G, De Sio M, Cheng L, Montironi R (2009) Pathology of the prostate in radical cystectomy specimens: a critical review. Surg Oncol 18:73-84. doi: 10.1016/j.suronc.2008.07.006 S0960-7404(08)00063-7

4. Aytac B, Vuruskan H (2011) Clinicopathologic features of incidental prostatic adenocarcinoma in radical cystoprostatectomy specimens. World J Surg Oncol 9:81. doi:10.1186/1477-7819-9-811477-7819-981

5. Barbisan F, Mazzucchelli R, Scarpelli M, Lopez-Beltran A, Cheng L, Kirkali Z, Montironi R (2009) Urothelial and incidental prostate carcinoma in prostates from cystoprostatectomies for bladder cancer: is there a relationship between urothelial and prostate cancer? BJU Int 103:1058-1063. doi:10.1111/j.1464-410X.2008.08207.xBJU8207

6. Bruins HM, Djaladat H, Ahmadi H, Sherrod A, Cai J, Miranda G, Skinner EC, Daneshmand S (2013) Incidental cancer of the prostate in patients with bladder urothelial carcinoma: comprehensive analysis of 1476 radical cystoprostatectomy specimens. J Urol. doi:10. 1016/j.juro.2013.05.034

7. Bubendorf L, Schopfer A, Wagner U, Sauter G, Moch H, Willi N, Gasser TC, Mihatsch MJ (2000) Metastatic patterns of prostate cancer: an autopsy study of 1,589 patients. Hum Pathol 31:578-583

8. Buse S, Hofner T, Muller SC, Hermann E, Wieland WF, May M, Stief CG, Bastian PJ, Hohenfellner M, Haferkamp A (2013) Characterization and risk stratification of prostate cancer in patients undergoing radical cystoprostatectomy. Int J Urol. doi:10.1111/iju. 12073

9. Chun TY (1997) Coincidence of bladder and prostate cancer J Urol 157:65-67

10. Colombo R, Bertini R, Salonia A, Naspro R, Ghezzi M, Mazzoccoli B, Deho F, Montorsi F, Rigatti P (2004) Overall clinical outcomes after nerve and seminal sparing radical cystectomy for the treatment of organ confined bladder cancer. J Urol 171:1819-1822. doi:10. 1097/01.ju.0000123781.49896.fe

11. Damiano R, Di Lorenzo G, Cantiello F, De Sio M, Perdona S, D'Armiento M, Autorino R (2007) Clinicopathologic features of prostate adenocarcinoma incidentally discovered at the time of radical cystectomy: an evidence-based analysis. Eur Urol 52:648-657. doi:10.1016/j.eururo.2007.06.016

12. Dirnhofer St. BL, Lehr HA, Landau B, Zenklusen HR (2011) Qualitätsrichtlinien SGpath

13. Ferlay J, Steliarova-Foucher E, Lortet-Tieulent J, Rosso S, Coebergh JW, Comber H, Forman D, Bray F (2013) Cancer incidence and mortality patterns in Europe: estimates for 40 countries in 2012. Eur J Cancer 49:1374-1403. doi:10.1016/j.ejca.2012.12.027S09598049(13)00007-5 
14. Fritsche HM, Aziz A, Eder F, Otto W, Denzinger S, Wieland WF, May M, Hofstadter F, Hartmann A, Burger M (2012) Potentially clinically relevant prostate cancer is found more frequently after complete than after partial histopathological processing of radical cystoprostatectomy specimens. Virchows Arch 461:655-661. doi: 10.1007/s00428-012-1328-6

15. Gakis G, Schilling D, Bedke J, Sievert KD, Stenzl A (2010) Incidental prostate cancer at radical cystoprostatectomy: implications for apex-sparing surgery. BJU Int 105:468-471. doi:10.1111/j.1464410X.2009.08739.xBJU8739

16. Jin XD, Chen ZD, Wang B, Cai SL, Yao XL, Jin BY (2008) Incidental prostate cancer in radical cystoprostatectomy specimens. Asian J Androl 10:809-814. doi:10.1111/j.1745-7262. 2008.00420.x

17. Kurokawa K, Ito K, Yamamoto T, Takechi H, Miyamoto S, Suzuki K, Yamanaka H (2004) Comparative study on the prevalence of clinically detectable prostate cancer in patients with and without bladder cancer. Urology 63:268-272. doi:10.1016/j.urology.2003. 09.027S009042950301015X

18. Mazzucchelli R, Barbisan F, Scarpelli M, Lopez-Beltran A, van der Kwast TH, Cheng L, Montironi R (2009) Is incidentally detected prostate cancer in patients undergoing radical cystoprostatectomy clinically significant? Am J Clin Pathol 131:279-283. doi:10.1309/ AJCP4OCYZBAN9TJUP06J2Q5065544X5J

19. Montironi R, Cheng L, Mazzucchelli R, Scarpelli M, Kirkali Z, Montorsi F, Lopez-Beltran A (2009) Critical evaluation of the prostate from cystoprostatectomies for bladder cancer: insights from a complete sampling with the whole mount technique. Eur Urol 55: 1305-1309. doi:10.1016/j.eururo.2008.10.032S0302-2838(08) 01251-7

20. Nakagawa T, Kanai Y, Komiyama M, Fujimoto H, Kakizoe T (2009) Characteristics of prostate cancers found in specimens removed by radical cystoprostatectomy for bladder cancer and their relationship with serum prostate-specific antigen level. Cancer Sci 100:18801884. doi:10.1111/j.1349-7006.2009.01267.x

21. Pignot G, Salomon L, Neuzillet Y, Masson-Lecomte A, Lebacle C, Patard JJ, Lunardi P, Rischmann P, Pasticier G, Bernhard JC, Cohen J, Timsit MO, Verkarre V, Peyronnet B, Verhoest G, Le Goux C, Zerbib M, Brecheteau F, Bigot P, Larre S, Murez T, Thuret R, Lacarriere E, Champy C, Roupret M, Comperat E, Berger J, Descazeaud A, Toledano H, Bastide C, Lavilledieu S, Avances C, Delage F, Valeri A, Molimard B, Houlgatte A, Gres P, Donnaint A,
Kleinclauss F, Legal S, Doerfler A, Koutlidis N, Cormier L, Hetet JF, Colls P, Arvin-Berod A, Rambeaud JJ, Quintens H, Soulie M, Pfister $\mathrm{C}$, The members of The Oncologic Committee of the French Association of U (2013) Clinicopathological characteristics of incidental prostate cancer discovered from radical cystoprostatectomy specimen: a multicenter French study. Ann Surg Oncol. doi:10.1245/ s10434-013-3340-8

22. Ploussard G, Epstein JI, Montironi R, Carroll PR, Wirth M, Grimm MO, Bjartell AS, Montorsi F, Freedland SJ, Erbersdobler A, van der Kwast TH (2011) The contemporary concept of significant versus insignificant prostate cancer. Eur Urol 60:291-303. doi:10.1016/j. eururo.2011.05.006S0302-2838(11)00495-7

23. Quinn M, Babb P (2002) Patterns and trends in prostate cancer incidence, survival, prevalence and mortality. Part II: individual countries. BJU Int 90:174-184

24. R CT (2013) A language and environment for statistical computing. R Foundation for Statistical Computing, Vienna, Austria. URL http:// www.R-project.org/

25. Sakr WA, Grignon DJ, Crissman JD, Heilbrun LK, Cassin BJ, Pontes JJ, Haas GP (1994) High grade prostatic intraepithelial neoplasia (HGPIN) and prostatic adenocarcinoma between the ages of 20-69: an autopsy study of 249 cases. In Vivo 8:439-443

26. Singh A, Kinoshita Y, Rovito PM Jr, Landas S, Silberstein J, Nsouli I, Wang CY, Haas GP (2008) Higher than expected association of clinical prostate and bladder cancers. J Urol 179:S2-S5. doi:10. 1016/j.juro.2008.03.130S0022-5347(08)00731-3

27. Sruogis A, Ulys A, Smailyte G, Kardelis Z, Kulboka A, Anglickiene G, Samalavicius N, Anglickis M (2012) Incidentally found prostate cancer and influence on overall survival after radical cystoprostatectomy. Prostate Cancer 2012:690210. doi:10.1155/ 2012/690210

28. WHO (2008) Estimated cancer incidence, mortality, prevalence and disability-adjusted life years (DALYs) worldwide in 2008

29. Winkler MH, Livni N, Mannion EM, Hrouda D, Christmas T (2007) Characteristics of incidental prostatic adenocarcinoma in contemporary radical cystoprostatectomy specimens. BJU Int 99:554-558. doi: 10.1111/j.1464-410X.2006.06660.x

30. Zhu YP, Ye DW, Yao XD, Zhang SL, Dai B, Zhang HL, Shen YJ, Zhu Y, Shi GH (2009) Prevalence of incidental prostate cancer in patients undergoing radical cystoprostatectomy: data from China and other Asian countries. Asian J Androl 11:104-108. doi:10.1038/aja. 2009.15aja200815 